\title{
LONG TERM EFFECTS OF LOW-LEVEL SARIN INHALATION EXPOSURE ON THE SPATIAL MEMORY OF RATS IN A T-MAZE
}

\begin{abstract}
Jiř́ Kassa, Marie Koupilová, Josef Vachek
Purkyně Military Medical Academy in Hradec Králové: Department of Toxicology

Summary: 1. To study the influence of low-level sarin exposure on cognitive functions, male albino Wistar rats were exposed to three various low concentrations of sarin (LEVEL 1-3) for 60 minutes in the inhalation chamber. Testing of cognitive functions was carried out using the T-maze evaluating learning and spatial memory. The behavior of sarin-exposed rats in the T-maze was tested several times within five weeks following sarin inhalation exposure to look for any cognitive impairments. The alteration of cognition was evaluated by using a method studying memory elicitation in response to appetitive motivation in a multiple T-maze. 2. Statistically significant, short-term deficiency in the T-maze performance was observed in rats exposed to symptomatic (LEVEL 3 ) as well as clinically asymptomatic concentration (LEVEL 2) of sarin. The repeated exposure of rats to clinically asymptomatic dose of sarin (LEVEL 2R) did not change the effect of lowlevel sarin exposure on spatial memory compared to the single exposure to the same dose of sarin. 3. Thus, sarin is able to influence the cognitive functions (e.g. spatial memory) even at low doses that do not cause clinically manifested intoxication following the inhalation exposure. Nevetheless, the alteration of spatial memory lasts for a short time only, in contrast with the severe sarin poisoning.
\end{abstract}

Key words: Sarin; Low-level inhalation exposure; Spatial memory; T-maze; Rat

\section{Introduction}

The potential for the exposure to highly toxic organophosphorus compounds (OPs), called nerve agents, exists on the battlefield (e.g. Iran-Iraq war) as well as in a civilian sector as a threat by a terrorist group (e.g. Tokyo subway incident - 12) or as an accident as a part of current demilitarization efforts. OPs elicit their toxic effects by irreversible inhibiting acetylcholinesterase (AChE, EC 3.1.1.7) in the central as well as peripheral nervous system allowing accumulation of acetycholine (ACh), excessive stimulation of postsynaptic cholinergic receptors and consequent signs of neurotoxicity. Signs of acute toxicity with extensive AChE inhibition include autonomic dysfunction (e.g. excessive salivation, lacrimation, urination and defecation), involuntary movements (e.g. tremor, fasciculation), respiratory dysfunction and other signs and symptoms $(9,19)$.

OP-induced cholinergic effects are usually manifested immediately following high-level exposure $(9,19)$, nevertheless, there are numerous studies in both humans and animals showing that survivors of high-level OP exposure can experience subtle but significant long-term neurological and neuropsychological outcomes that are detectable months or even years following the recovery from acute poisoning (2). The rapid onset of signs and symptoms of poisoning following OP exposure can be explained in terms of
ACh accumulation following AChE inhibition but no mechanism has been identified for the induction of long term effects. In addition, very little is known about possible neurological and neuropsychological effects including the impairments of cognitive functions of single or repeated low-level, asymptomatic exposure to OPs. The purpose of this study is to find out whether a nerve agent sarin might cause adverse effects on cognitive functions following the single or repeated low-level inhalation exposure in rats.

\section{Material and methods}

Male albino Wistar rats weighing 180-200 g were purchased from VÚFB Konárovice (Czech Republic). They were kept in an air-conditioned room and allowed access to standard food and tap water ad libitum. The rats were divided into groups of ten. Handling of the experimental animals was done under supervision of the Ethics Committee of the Medical Faculty of Charles University and the Purkyně Military Medical Academy in Hradec Králové (Czech Republic).

The rats were exposed to various low concentrations of sarin (obtained from Military Technical Institute, Zemianské Kostolany, Slovak Republic) for 60 minutes in the inhalation chamber. Three low concentrations of sarin were chosen: 
- clinically nad laboratory asymptomatic concentration $(0.8 \mu \mathrm{g} / \mathrm{L})$ - LEVEL 1

- clinically asymptomatic concentration with a significant inhibition of erythrocyte AChE by $30 \%$ ( $1.25 \mu \mathrm{g} / \mathrm{L})$ - LE-

VEL 2. This concentration was used for a single (LEVEL 2) or repeated (three times during one week) exposure (LEVEL 2R)

- non-convulsive symptomatic concentration $(2.5 \mu \mathrm{g} / \mathrm{L})$ LEVEL 3

Cognitive functioning was tested using a T-maze, consisting of five segments, a starting and a goal compartment to evaluate learning, spatial memory and spatial orientation $(6,7)$. The rats were trained, with the food reward, to run through the maze in less than 10 seconds without entering the side arm. The time necessary to reach the goal box was recorded. Before inhalation exposure to sarin, the rats were trained to reach the goal box as soon as possible by moving to the correct segment in the T-maze. It usually took 4-6 weeks of training to reach the criterion which was $80 \%$ or more correct behavior. The exposure started the day after the animals had reached this criterion. The spatial memory was tested 1 hour, 2 hours, 1 day and 1 week following the sarin inhalation exposure and then, once a week till the end of the fifth week following the exposure. The time of reaching the goal box by sarin-exposed rats was compared to the values obtained from the same rats immediately before sa- rin exposure and from control rats exposed to pure air instead of sarin.

Analysis of variance (ANOVA) with Bonfferoni's corrections for multiple comparisons was used for the determination of significant differences between experimental and control values (1). The differences were considered significant when $\mathrm{P}<0.05$.

\section{Results}

While the rats exposed to LEVEL 1 of sarin did not show any significant changes in the rapidity of spatial discrimination in T-maze following their exposure in comparison with the control rats exposed to the pure air, the significant impairment of spatial memory of rats exposed to other low concentrations of sarin (LEVEL 2 and 3) was observed. The results of the influence of various sarin concentrations on the T-maze performance of rats following single inhalation exposure are shown in Figure 1. While a spatial memory of rats exposed to LEVEL 1 of sarin was not significantly influenced, rats exposed to LEVEL 2 and 3 of sarin showed a significant decrease in T-maze performance for a short time (till the first day following the exposure). Their latency time in the choice of the correct segment and reaching the goal box of the T-maze was extended. In addition, the effects of low-level sarin inhalation

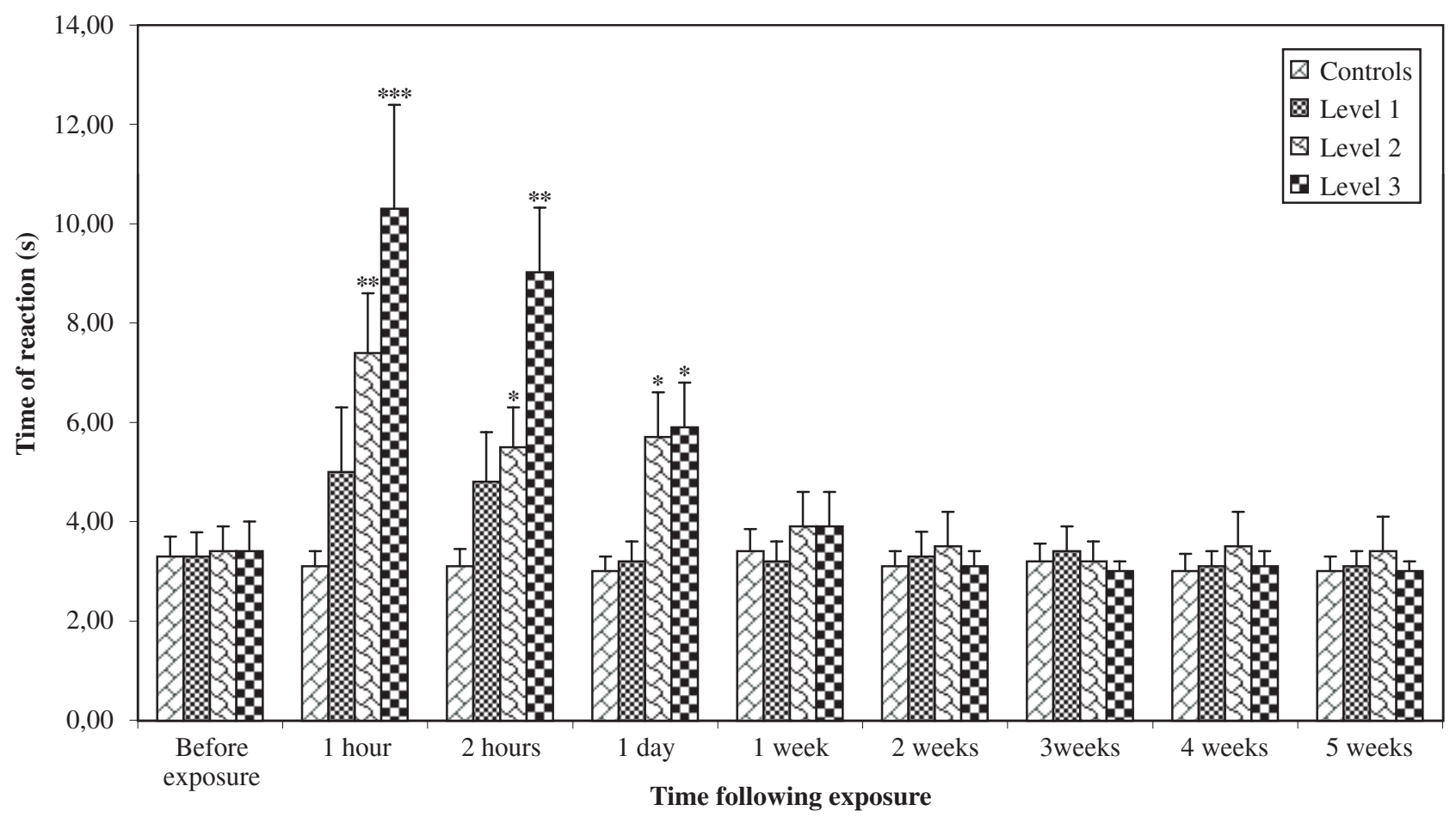

Fig. 1: The changes in the T-maze performance of rats singly exposed to sarin at LEVEL 1 - 3 in comparison with control rats. Statistical significance: * $\mathrm{P}<0.05,{ }^{* *} \mathrm{P}<0.01,{ }^{* * *} \mathrm{P}<0.001$. 
exposure was dose-dependent. When the rats were exposed to LEVEL 3 of sarin, their time of passage through the maze was more lengthened at 1 and 2 hours following the inhalation exposure compared to the rats exposed to LEVEL 2 of sarin (Fig. 1).

The results of T-maze performance of rats repeatedly exposed to LEVEL 2 of sarin are given in Figure 2. The repeated exposure of rats to clinically asymptomatic concentration of sarin (LEVEL 2) did not change the effect of low-level sarin exposure on spatial memory in comparison with the single exposure to the same dose of sarin (Fig. 2).

\section{Discussion}

The exposure to high doses of OPs has been demonstrated to result in severe brain neuropathology that involves not only neuronal degeneration and necrosis of various brain regions $(8,11,13)$ but also persistent severe alteration in behavior and cognitive functions, especially impairment of learning and memory $(4,10,16)$. The most significant injury caused by OP poisoning is neuronal degeneration of the hippocampus that is associated with the spatial learning and memory. Therefore, impairment of cognitive functions, especially incapacitation of learning and memory, belongs to the most frequent central signs of acute OP poisoning $(9,10)$. In addition, the adverse effects of OP compounds on cognitive functions, such as learning and memory, may persist for a relatively long time following the termination of toxicant exposure. The results from several studies have demonstrated the presence of OP-induced learning impairments several days after the behavioral signs of OP toxicity have subsided $(3,4,10)$. The chronic exposure to OP compounds can also result in specific long-term cognitive deficits even when signs and symptoms of excessive cholinergic activity are not present $(14,15)$. Recently, the ability of a nerve agent sarin to cause subtle long-term neurobehavioral and neurophysiological effects in rats exposed to its low level without a significant inhibition of AChE activity and a clinically manifested alteration of cholinergic nervous system has been described (5).

Our data clearly demonstrate that sarin is also able to induce dose-dependent alteration of cognitive functions in the case of the inhalation exposure of rats to its low concentrations. The adverse effect of low-level sarin inhalation exposure was manifested in the time determining rate of orientation (latency time). Therefore, the significant, clinically manifested AChE inhibition in the central nervous system leading to the neuronal degeneration of some brain regions including hippocampus, associated with the spatial learning and memory, is not necessary for the clinically manifested cognitive impairments. These findings correspond with earlier published data about neurological and neurophysiological outcomes detectable months or even years following recovery from acute OP poisoning $(17,20)$. In addition, a current study attempts to show a temporal rela-

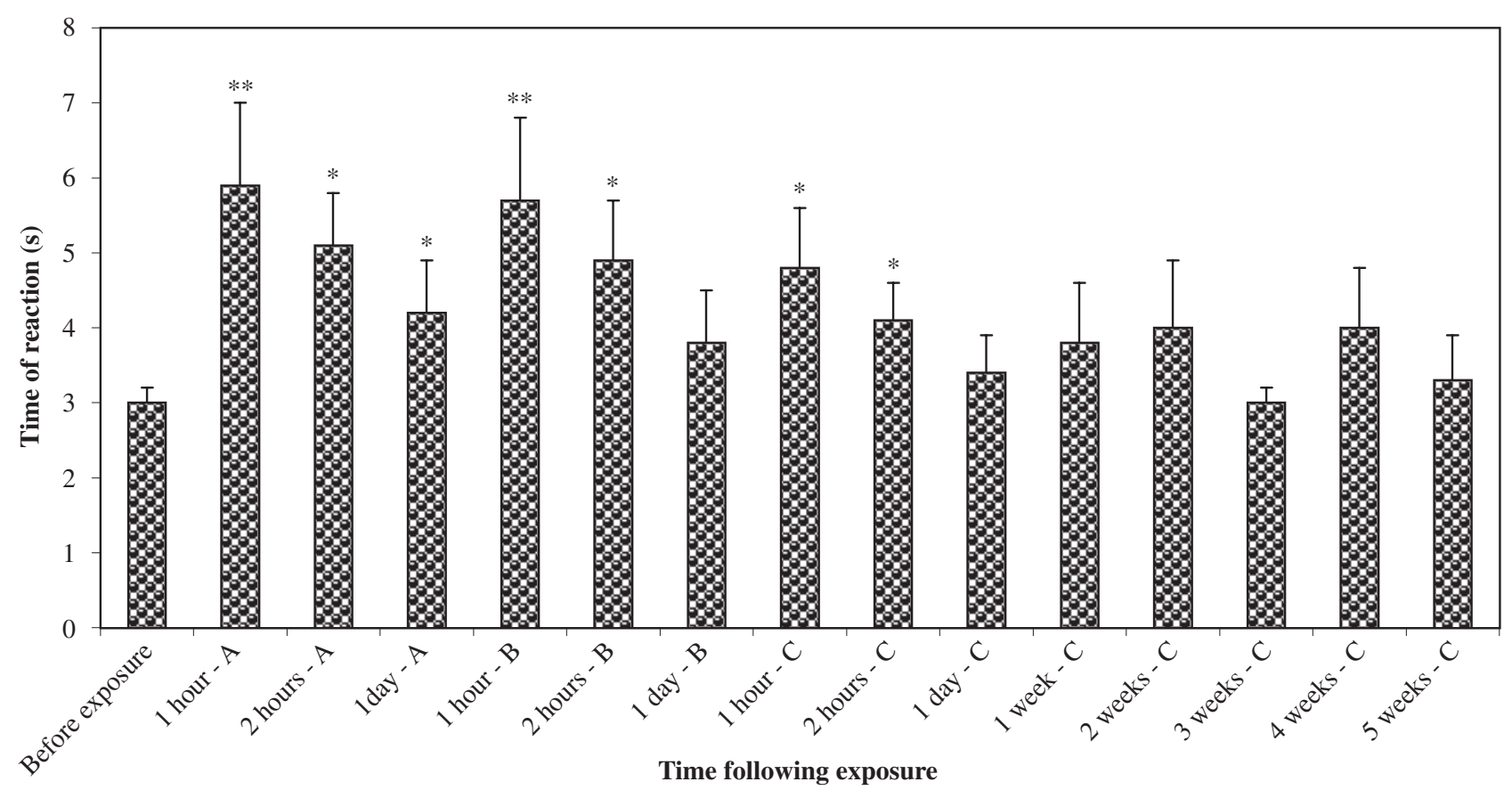

Fig. 2: The alteration of the T-maze performance in rats repeatedly exposed (A - the first exposure, B - the second exposure, $\mathrm{C}$ - the third exposure) to LEVEL 2 of sarin. Statistical significance - see Figure 1. 
tionship between OP-induced impairment in performance of a spatial memory task and the protracted decrease in the expression of cholinergic receptors in specific brain regions caused by asymptomatic exposure to an OP compound (18).

Although these findings are difficult to extrapolate directly to human low-level exposures to OPs, they indicate that short cognitive impairments without clinically manifested disturbance of central cholinergic nervous system could occur in humans following the inhalation exposure to clinically asymptomatic concentrations of sarin.

\section{Aknowledgements}

The authors thank to Mrs. H. Antlová and Mrs. E. Vodáková for their skilful technical assistance and to Mgr. V. Bláha for the statistical evaluation.

This study was supported by the grant of Ministry of Defence, No. 03021100006.

\section{References}

1. Afifi AA, Azen SP. Statistical analysis and computer oriented approach. $2^{\text {nd }}$ ed New York: Academic Press, 1979:442-5.

2. Brown MA, Kelley AB. Review of health consequences from high-, intermediateand low-level exposure to organophosphorus nerve agents. J Appl Toxicol 1998;18:393-408.

3. Buccafusco JJ, Heithold DL, Chon SH. Long-term behavioral and learning abnormalities produced by the irreversible cholinesterase inhibitor soman: effect of a standard pretreatment regimen and clonidine. Toxicol Lett 1990;52:319-29.

4. Bushnell PJ, Padilla SS, Ward T, Pope CN, Olszyk VB. Behavioral and neurochemical changes in rats dosed repeatedly with diisopropylfluorophosphate. J Pharmacol Exp Ther 1991;256:741-50.

5. Kassa J, Pecka M, Tichý M, Bajgar J, Koupilová M, Herink J, Kročová Z. Toxic effects of sarin in rats at three months following single or repeated low-level inhalation exposure. Pharmacol Toxicol 2001;88:209-12 .

6. Koupilová M, Herink J. Effects of mescaline and its derivative N-(3,4,5- trimet hoxyethyl)-aziridine on the spatial orientation of rats in T-maze. Physiol Bohem 1989;38:497-502.

7. Koupilová M, Herink J. An attempt to antagonize DSP-4 induced impairment of the performance of rats in a T-maze. Homeostasis 1995;36:41-2.
8. Lemercier G, Carpentier P, Sentenac-Roumanou H, Morelis P. Histological and histochemical changes in the central nervous system of the rat poisoned by an irreversible anticholinesterase organophosphorus compound. Acta Neuropathol 1983;61:123-9.

9. Marrs TC. Organophosphate poisoning. Pharmacol Ther 1993;58:51-66

10. McDonald BE, Costa LG, Murphy SD. Spatial memory impairment and central muscarinic receptor loss following prolonged treatment with organophosphates. Toxicol Lett 1988;40:47-56.

11. McLeod CG, Singer AW, Harrington DG. Acute neuropathology in soman poisoned rats. Neurotoxicology 1982;297:681-3.

12. Ohtomi S, Takase M, Kunagoi F. Sarin poisoning in Japan. A clinical experience in Japan Self Defense Force (JSDF) Central Hospital Int Rev Arm For Med Ser 1996;69:97-102.

13. Petras JM. Soman neurotoxicity. Fundam Appl Toxicol 1981;1:242-9.

14. Prendergast MA, Terry AV, Buccafusco JJ. Chronic, low-level exposure to diisopropylfluorophosphate causes protracted impairment of spatial navigation learning. Psychopharmacology 1997;130:276-84.

15. Prendergast MA, Terry AV, Buccafusco JJ. Effects of chronic, low-level organophosphate exposure on delayed recall, discrimination and spatial learning in monkeys and rats. Neurotoxicol Teratol 1998;20:115-22.

16. Rafaelle K, Olton D, Annau Z. Repeated exposure to diisopropylfluorophosphate (DFP) produces increased sensitivity to cholinergic antagonists in discrimination retention and reversal. Psychopharmacology (Berlin) 1990;100:267-74.

17. Savage EP, Keefe TJ, Mounce LM, Heaton RK, Lewis JA, Burcar PJ. Chronic neurological sequelae of acute organophosphate pesticide poisoning. Arch Environ Health 1988;43:38-45.

18. Stone JD, Terry AVJr, Pauly JR, Prendergast MA, Buccafusco JJ. Protractive effects of chronic treatment with an acutely subtoxic regimen of diiopropylfluorophosphate on the expression of cholinergic receptor densities in rats. Brain Res 2000;882:9-18

19. Taylor P. Anticholinesterase agents. In: Hardman JG, Limbird LE (eds): The Pharmacological Basis of Therapeutics, th $^{\text {th }}$ ed. New York: McGraw Hill, 1996:161-76.

20. Yokoyama $\mathrm{K}$, Araki S, Murata $\mathrm{K}$ et al. Chronic neurobehavioral and central and autonomic nervous system effects in Tokyo subway sarin poisoning. J Physiol (Paris) 1998; 92:317-23

Submitted May 2001.

Accepted November 2001.

Doc. MUDr. Jiři Kassa, CSc., Purkyně Military Medical Academy, P.O. Box 35/T, 50001 Hradec Králové, Czech Republic. e-mail: kassa@pmfhk.cz 